\title{
Contribuições da Atividade Orientadora de Ensino para a Educação do Campo
}

\author{
Contributions of the Teaching-Orienteering Activity \\ to Rural Education
}

Algacir José Rigon ${ }^{1}$

\begin{abstract}
RESUMO
O presente estudo objetivou explicitar alguns pressupostos fundamentais da Educação do Campo e da Atividade Orientadora de Ensino (AOE). Com isso, procura-se demonstrar que a possibilidade de emancipação humana e transformação social, especialmente no que diz respeitos aos povos do campo, passa pela atividade educativa, sendo que a $\mathrm{AOE}$ é um meio fundamental para que esse processo ocorra satisfatoriamente.
\end{abstract}

Palavras-chave: Educação do Campo. Atividade Orientadora de Ensino. Atividade Pedagógica.

\begin{abstract}
The present study aimed to explain some fundamental assumptions of Rural Education and Teaching-Orienteering Activity (AOE). This demonstrates that the possibility of human emancipation and social transformation, especially with regard to the people of the countryside, passes through educational activity, and $\mathrm{AOE}$ is a fundamental means for this process to occur satisfactorily.
\end{abstract}

Keywords: Rural Education. TeachingOrienteering Activity. Pedagogical Activity.

\section{Introdução}

A perspectiva da inclusão social trouxe boas novas para as classes populares, especificamente às populações campesinas por meio de algumas Políticas Públicas, incluindo os Cursos de Educação do Campo, voltados para atender às demandas desse público que - historicamente - ficou alijado da atenção dos governos. A formação de professores e a educação são o alicerce desse projeto cujo objetivo, além de oferecer formação pública, gratuita e de qualidade (acesso ao saber produzido historicamente pela humanidade), é a constituição de uma sociedade democrática, livre das desigualdades sociais e dos processos segregatórios. Os movimentos

1 Prof. Dr. Algacir José Rigon, Universidade Federal do Pampa - UNIPAMPA, Brasil. https://orcid.org/0000-0002-8745-6283. E-mail: ajrigon@gmail.com. 
progressistas, nacionalistas e de cunho popular, em suas inúmeras lutas na tentativa de ganhar protagonismo, foram se apropriando do arcabouço teórico disponível; contudo, sem averiguar se esses elementos os conduziriam para a tão sonhada transformação social, ou - simplesmente - a um processo de reprodução das condições sociais vigentes de exploração e alienação.

Ao pensar uma proposta de educação, precisa-se compreender a realidade, diagnosticar para qual cenário se está projetando a respectiva proposta pedagógica, saber em quais circunstâncias ocorrem os processos pedagógicos. Primeiramente, aparece o capitalismo, e sua versão mais recente - a perspectiva do neoliberalismo - naquilo que seguramente estrutura este sistema: a divisão em classes sociais, resultante, no caso do Brasil, da dominação portuguesa. Conforme Caio Prado Junior (1977), em seu nascimento, o país é fortemente capitalista, especialmente por fazer parte do mercado internacional, seja na questão do comércio de escravos seja na questão do comércio em geral. Os resquícios de uma sociedade sem classes (povos indígenas que aqui habitavam), ou até no sentido do feudalismo, foram ficando no passado e substituídas pelo capitalismo em suas diferentes manifestações e organizações. Especialmente com o advento da Lei Áurea, os camponeses ligados à terra foram se tornando camponeses enquanto operários, enquanto trabalhadores assalariados. Sendo assim, as classes sociais têm um aspecto histórico: nem sempre existiram e nem sempre existirão, sendo que apenas fazem parte desse arranjo das relações sociais humanas, determinadas por essas circunstâncias.

Um segundo quesito para o trabalho educativo é mirar no horizonte, onde se quer chegar: a organização social e a formação humana almejada. Nesse caso, aponta-se como relevante almejar uma sociedade sem classes ou, ao menos, que haja a diminuição das desigualdades com o que haveria mais justiça social. Isso se compreende como uma das tarefas da educação. Enquanto trabalho educativo escolar, sua especificidade é possibilitar aos indivíduos que se apropriem da cultura, do conhecimento e dos saberes desenvolvidos pela humanidade ao longo da sua existência. Conforme Saviani (2003, p. 13), a especificidade do trabalho 
educativo consiste no "[...] ato de produzir, direta e intencionalmente, em cada indivíduo singular, a humanidade que é produzida histórica e coletivamente pelo conjunto dos homens". Essa atividade consiste num processo de mediação entre o indivíduo e a cultura humana, realizado de forma intencional de modo a garantir a universalização do gênero humano. Nesse sentido, quais atividades de ensino e aprendizagem, realizadas de modo intencional, podem desencadear esse processo de humanização? Quais atividades estão afinadas com uma perspectiva de transformação social? Especialmente, como organizar o processo educativo para que atenda as perspectivas e o contexto do campo e dos camponeses?

Um terceiro elemento diz respeito à importância de aprender com a história, aprender com as experiências do passado que estão em sintonia com as perspectivas postas anteriormente: compreender o sistema capitalista (sua versão neoliberal e totalitarista) e superar as classes e as desigualdades sociais impostas por este sistema. Alguns princípios fundamentais que servem de balizadores para as propostas educacionais, especialmente as que miram uma transformação desse sistema e a superação da sociedade de classes (desigualdade social), encontram-se nas teorias e pedagogias socialistas, em alguns de seus autores, bem como em experiências de Movimentos Sociais, a exemplo do Movimento dos Trabalhadores Rurais Sem Terra (MST).

\section{Da Educação do Campo: definições e princípios gerais}

O berço da Educação do Campo é a luta dos camponeses, organizados coletivamente em movimentos sociais, especialmente do MST - na década de 80 , que lapidou uma concepção de educação a partir da luta pela terra e por políticas públicas que atendessem às circunstâncias de vida no campo. Essa nova concepção se contrapõe, em suas linhas gerais, à Educação Rural, que oferecia uma educação urbana estendida às populações do campo sem - contudo considerar o contexto de vida e suas particularidades. A Educação Rural, no Brasil, aparece desde a Proclamação da República; acontece atrelada às preocupações de conter o êxodo rural, da formação agronômica, mas não a de 
respeito à identidade dos povos do campo; tampouco atendendo às demandas das populações campesinas que, para acessar a escola, percorrem grandes distâncias e a acessam num modelo urbanocêntrico e industrial-desenvolvimentista. De outra forma, a Educação Rural se desenvolveu a partir da perspectiva do capitalismo agrário em que os camponeses são subalternos aos interesses do capital; em contrapartida, os movimentos camponeses passaram a lutar por

[...] uma educação que seja no e do campo. No: o povo tem o direito a ser educado no lugar onde vive; Do: o povo tem o direito a uma educação pensada desde seu lugar e com a sua participação, vinculada à sua cultura e às suas necessidades humanas e sociais. Somos herdeiros e continuadores da luta histórica pela constituição da educação como um direito universal, de todos: um direito humano, de cada pessoa em vista de seu desenvolvimento pleno, e um direito social, de cidadania ou de participação mais crítica e ativa na dinâmica da sociedade. Como direito não pode ser tratada como serviço nem como política compensatória; muito menos como mercadoria (CALDART, 2002, p. 18)

Como pressuposto desta concepção está um processo educativo que reconheça os povos do campo, suas identidades e suas organizações, suas comunidades; sem, contudo, utilizar esses povos como meios para formação de mão de obra a serviço do mercado, dos interesses escusos das "empresas rurais" e dos interesses do capital.

A Educação do Campo - ainda - é forjada nas lutas sociais camponesas que se inicia justamente com a luta pela terra e pela Reforma Agrária, lutas de resistência e por melhores condições de trabalho, luta para que se continue sendo agricultores, com identidade própria, e não expropriados de seus bens, especialmente quando não há políticas públicas e são expropriados da terra, restando-lhes vender a força de trabalho como mercadoria e condição para sobreviver. Não mais possuidor da terra, enquanto um meio de produção e de outros meios de produção, o camponês submeteu-se aos que a possuíam² ${ }^{2}$ No caso dos indígenas, a expropriação ocorreu no

\footnotetext{
$2 \mathrm{O}$ camponês submeteu-se aos que possuíam a terra, enquanto meio de produção. Pelas condições de vida no campo, geralmente com pouca terra e parcos conhecimentos, ficou sem condições de produzir o suficiente para sustentar a família (economia familiar); sem acesso à saúde e educação (escolas próximas), viu a necessidade de ir para a cidade e vendeu sua propriedade rural. Contudo, não teve acesso ao sonho prometido, não teve sucesso na cidade, não consegue mais retornar ao campo e, de um modo geral, engrossa a periferia e as fileiras do desemprego. Obutchénie: R. de Didat. e Psic. Pedag.| Uberlândia, MG |v.4| n.2 | p.310-333| maio/ago. 2020 ISSN: 2526-7647 
doloroso processo de colonização, assim como os quilombolas, frutos do processo escravo no Brasil; dos demais, pelos processos oriundos da modernização industrial capitalista e exploração de uma classe sobre a outra (tendência de concentração da terra, dos recursos naturais e da renda).

Enquanto movimento de resistência se quer uma educação a serviço do homem e, rearticulando o trabalho manual e a atividade intelectual, voltada plenamente à formação integral do homem. Nesse sentido, em vista de um projeto estratégico é que se coloca, desde já, a defesa intransigente de uma educação estatal, gratuita, laica, obrigatória e universal para todas as crianças, jovens e adultos, acesso à educação em todos os níveis de ensino. Educação para e pelos camponeses organizados! É isso o que se propõe em termos de educação revolucionária em que, além do processo de escolarização e apropriação dos bens culturais desenvolvidos pela humanidade, ocorra formação política para a luta revolucionária.

A Educação Revolucionária ou Educação Política, na concepção leninista, pode ser inferida tanto a partir de sua clássica máxima "Aprender, aprender, aprender sempre" ou a partir da obra Que fazer?:

Em particular, os dirigentes deverão instruir-se cada vez mais em todas as questões teóricas, libertar-se cada vez mais da influência da fraseologia tradicional, própria da antiga concepção do mundo, e ter sempre presente que o socialismo, desde que se tornou uma ciência, exige ser tratado como uma ciência, isto é, ser estudado. (LÊNIN, 1978, p. 35)

De outra forma, é preciso ter clareza de que a perspectiva socialista ou comunista não aflora naturalmente; tampouco, nas lutas econômicas travadas pelas classes operárias e camponesas. A tese é de que, pelo processo econômico espontaneísta, apenas se conduzem as lutas reivindicativas cujos resultados são da mesma ordem; o estado capitalista representa e organiza a dominação da classe burguesa e o faz moderando e amortecendo os conflitos entre as classes. Por isso, como medida para sobreviver e permanecer estável, o estado pode fazer concessões econômicas às reivindicações dos trabalhadores. Alguns críticos da concepção marxista de estado afirmam que o estado não atende às demandas da 
burguesia, pois algumas instituições do estado, direito, justiça e o ministério do trabalho, institutos da previdência social atendem aos interesses dos trabalhadores; contudo, esquecem que esses aspectos estão atrelados ao interesse econômico, minimamente atendido, concessões econômicas que são efetivadas para amenizar a luta de classes. O acesso aos meios de produção, socialização dos meios de produção e a superação do sistema capitalista, que compõem o interesse político, esses quesitos não podem ser e não são concedidos, contemplados pelo estado burguês, por que isso seria a sua extinção.

Em vista disso que, para a revolução ou transformação social, precisa concorrer a educação política, a instrução política, que é a elevação cultural do povo de modo a garantir o desenvolvimento das forças produtivas e a socialização dos meios de produção. Há a necessidade de forçar para que os operários, trabalhadores, camponeses assumam as grandes frentes de luta, assumam como operários intelectuais, que se espalhassem nas diferentes frentes, à luz da teoria, formando a análise concreta da situação na qual estão inseridos, afinal, como já expressava Marx, quem era na análise, era na ação (muito embora quem acerta na análise, pode, mesmo assim, não acertar na proposição da ação, o acerto na análise é um passo importante). Nessa perspectiva, Lênin define que "devemos empreender ativamente o trabalho de educação política da classe operária, de desenvolvimento da sua consciência política" (1978, p. 68). O que por sua vez está ligado "à necessidade de desenvolver a consciência política em todos os seus aspectos". (LENIN, 1978, p. 68-69)

Consciência política e atividade revolucionária, transformadora, estão ligadas entre si, uma não existe sem a outra. A educação nessa ótica envolve esses dois aspectos: atividade e consciência. A expressão Educação do campo, nesse horizonte de discussão, congrega não só o resultado de anos de luta e resistência dos camponeses, mas também a formação que ocorreu e ocorre intrinsecamente - a esse processo, formação nos acampamentos, formação e instrução popular e coletiva. Luria (1990) em suas pesquisas nos "vilarejos remotos do Uzbequistão" e nas "regiões montanhosas de Kirghijia", nos fins da 
década de 1920 e começo da década de 1930, demonstra que as mudanças históricas, bem como as formas de organização da atividade (coletiva, trabalho) possibilitam a apropriação de novos conteúdos e também o desenvolvimento cognitivo (intelectual, psicológico). De outra forma, o trabalho social coletivo, a organização coletiva da vida ou a partir de alguma instrução sistemática,

[...] demonstram de maneira convincente que a estrutura da atividade cognitiva não permanece estática ao longo das diversas etapas do desenvolvimento histórico e as formas mais importantes de processos cognitivos - percepção, generalização, dedução, raciocínio, imaginação e auto-análise da vida interior - variam quando as condições da vida social mudam e quando rudimentos de conhecimento são adquiridos (LURIA, 1990, p. 215).

Ou, conforme a conclusão que Vigotski apontou no Manuscrito de 1929 em que

[...] atrás das funções psicológicas estão geneticamente as relações das pessoas, então: 1) é ridículo procurar centros especiais para as funções psicológicas superiores ou funções supremas no córtex (partes frontais - Pavlov); 2) deve explicá-las não com ligações internas orgânicas (regulação), mas de fora - daquilo a que a pessoa dirige a atividade do cérebro de fora, através de estímulos; 3) elas não são estruturas naturais, mas construções; 4) o princípio básico do trabalho das funções psíquicas superiores (da personalidade) é social do tipo interação (auto-estimulação, "entrar na posse do seu corpo", dominação) das funções, que tomou o lugar da interação das pessoas (VIGOTSKI, 2000, p. 27).

Com base nisso, infere-se - preliminarmente - que a consciência é condicionada pelo caráter social e histórico das atividades nas quais os indivíduos estão inseridos. Lênin arremata essa discussão apontando que o "proletariado instrui-se, educa-se, travando a sua luta de classes" (2009, p. 72).

Um dos pressupostos - portanto - da Educação do Campo na perspectiva da transformação social é a possibilidade de organização da vida coletiva levada a termo por meio do diálogo entre seus diversos sujeitos e/ou povos.

Conforme Decreto n. ${ }^{\circ}$ 7.352, de 4 de novembro de 2010, compõem os povos do campo:

[...] os agricultores familiares, os extrativistas, os pescadores 
artesanais, os ribeirinhos, os assentados e acampados da reforma agrária, os trabalhadores assalariados rurais, os quilombolas, os caiçaras, os povos da floresta, os caboclos e outros que produzam suas condições materiais de existência a partir do trabalho no meio rural. (BRASIL, 2020, p. 1)

Inclusive, importante destacar que foi a partir de 1997, com o I ENERA (Encontro Nacional de Educadores e Educadoras da Reforma Agrária) e no $1^{\circ}$ Congresso Nacional Por uma Educação do Campo em 1998, que se consolida o movimento e a articulação de luta pela Educação do Campo, por políticas públicas que atendessem a essa demanda, que - inicialmente - era por uma educação básica, mas que - posteriormente - se ampliou para que alcançasse todos os níveis da educação. Um marco documental importante que demonstra parte dessas conquistas da educação enquanto um direito são as Diretrizes Operacionais para a Educação Básica no Campo (2002) que traz como conceito:

A Educação do Campo, tratada como educação rural na legislação brasileira, tem um significado que incorpora os espaços da floresta, da pecuária, das minas e da agricultura, mas os ultrapassa ao acolher em si os espaços pesqueiros, caiçaras, ribeirinhos e extrativistas. $\mathrm{O}$ campo neste sentido, mais do que um perímetro não urbano, é um campo de possibilidades que dinamizam a ligação dos seres humanos com a própria produção das condições de existência social e com as realizações da sociedade humana. Portanto, investir na qualidade da educação nacional significa dar continuidade às políticas educacionais que promovem a capacitação dos professores e inovem a gestão escolar e as práticas pedagógicas nos diferentes espaços educativos (BRASIL, 2002, p. 08).

Na continuidade desse movimento, o II ENERA - em 2004 - se constitui em outro marco importante a partir do qual se estabelecem alguns princípios para a constituição da Educação do Campo em sua materialidade concreta (Campo - Políticas Públicas - Educação) constituído por três momentos distintos, simultâneos e complementares:

A Educação do Campo é negatividade - denúncia/resistência, luta contra. Basta (!) de considerar natural que os sujeitos trabalhadores do campo sejam tratados como inferiores, atrasados, pessoas de segunda categoria; que a situação de miséria seja o seu destino; que no campo não tenha escola, que seja preciso sair do 
campo para frequentar uma escola; que o acesso à educação se restrinja à escola, que o conhecimento produzido pelos camponeses seja desprezado como ignorância [...]. A Educação do Campo é positividade - a denúncia não é espera passiva, mas se combina com práticas e propostas concretas do que fazer: a educação, as políticas públicas, a produção, a organização comunitária, a escola [...]. A Educação do Campo é superação - projeto/utopia: projeção de uma outra concepção de campo, de sociedade, de relação campo e cidade, de educação, de escola. Perspectiva de transformação social e de emancipação humana' (CALDART, 2008, p. 48/49)

Sendo assim, podemos sintetizar a concepção da Educação do Campo colocando como ponto de partida - necessariamente - o debate do campo, da questão agrária, especificamente aquilo que está relacionado com o trabalho no campo e as circunstâncias reais de vida no campo, seja no aspecto da luta pela terra enquanto acesso aos meios de produção da vida seja no aspecto do trabalho assalariado e precarizado. A esse ponto se unem os demais, especialmente, a educação, a partir do momento em que a atividade coletiva (trabalho) redunda num processo formativo, o trabalho enquanto princípio educativo (Gramsci e a Escola Unitária), a percepção do vínculo estabelecido entre a educação e os processos produtivos.

A relação entre educação e trabalho não é uma questão exclusiva das perspectivas socialistas; o capitalismo, no horizonte liberal, já havia consolidado uma proposta educativa que atendesse aos interesses de um modelo de desenvolvimento e de relações de trabalho do mercado capitalista, recentemente, do capital financeiro. Portanto, a relação campo e educação, trabalho camponês e educação precisa estar clara, pois pode servir de instrumentos para atender às demandas do capital, formação de mão de obra especializada, assim como fora a Educação Rural, voltada para atender às demandas produtivas e ao desenvolvimento do campo enquanto negócio, enquanto produtor de commodities. Nesse aspecto, a educação precisa estar vinculada a uma teoria e às concepções realmente emancipatórias, de formação humana ampla, omnilateral, que objetive a apropriação pelos sujeitos de todos os bens culturais produzidos pela humanidade ao longo do seu desenvolvimento.

O projeto de Educação do Campo em termos pedagógicos precisa superar 
a contradição entre trabalho manual e intelectual e entre cidade e campo, posta pela lógica capitalista burguesa e disseminada como "lógica escolar" muito presente nos momentos formativos quando se reverbera o ditado de que "na teoria é uma coisa, na prática é outra". Ou ainda, de que é preciso agir, fazer algo, que desemboca em certo ativismo, em certo pragmatismo que - no limite - é a reprodução do sistema vigente. A perspectiva contrária, de uma concepção sem engajamento político e compromisso com a comunidade, com o coletivo, será capenga e não contribuirá com a transformação social, com o desejo coletivo de mudança radical. De outra forma, ambas as perspectivas apontadas são concepções pseudopedagógicas.

Nessa discussão da Educação do Campo, o outro elemento da tríade é composto das políticas públicas de atendimento às demandas das populações camponesas. A escola - nesse horizonte - é uma política pública, um direito dos sujeitos e um dever do estado. A educação tem papel central na formação de sujeitos críticos, enquanto condição de por meio da formação oferecer instrumentos práticos e teóricos para que se pensem novas alternativas de desenvolvimento do campo, sem desconsiderar o coletivo; especialmente, a sustentabilidade ambiental contextualizada com os anseios da comunidade.

Em forma de síntese, podem-se anunciar como princípios filosóficos e pedagógicos da Educação do Campo, expostos explícita ou implicitamente anteriormente, os seguintes:

1. A defesa das conquistas do movimento socialista em termos de formação humanista e em termos de conhecimento.

2. A combinação da educação intelectual com a produção material, educação para o trabalho e pelo trabalho, ou ainda, a relação entre teoria e prática.

3. A educação deve propiciar aos homens o desenvolvimento integral de todas as potencialidades humanas.

4. As relações, inclusive as no interior da escola precisam se transformar, ou seja, passar das relações de competição para as de cooperação e para o apoio mútuo. 
5. A realidade social concreta, as circunstâncias históricas e de vida, são o ponto de partida da produção do conhecimento, mas também o seu ponto de chegada (enquanto realidade social concreta pensada, sistematizada).

6. O vínculo entre os processos educativos e os processos políticos, haja vista que a educação somente pode ser um ato de transformação social se estiver conectada com o engajamento político (perspectiva de transformar ou não o modo como a sociedade está organizada).

7. A inquietação ética-política diante da injustiça, da exclusão, da violência, da indignidade humana, pois se há condições no mundo (ou na comunidade) para se resolver um problema, a exemplo da fome, não resolvido, há um problema ético e de comprometimento político com o coletivo, para com a classe (operária e camponesa).

\section{Da Atividade Orientadora de Ensino: Seus fundamentos e o desenvolvimento coletivo}

A Atividade Orientadora de Ensino (AOE) foi elaborada inicialmente por Manoel Oriosvaldo de Moura - a partir de 1996 -; posteriormente, detalhada tanto pelo próprio autor quando pelos membros do Grupo de Estudos e Pesquisa da Atividade Pedagógica (GEPAPe) em vários artigos e teses. Diz Moura (2001, p. 155):

A atividade, na interpretação que fazemos desse conceito desenvolvido por Leontiev (1986), é fruto de uma necessidade que, para se realizar, estabelece objetivos, desencadeia ações, elege instrumentos e, por fim, avalia se chegou a resultados adequados ao que era desejado. A atividade orientadora de ensino tem uma necessidade: ensinar; tem ações: define o modo ou procedimentos de como colocar os conhecimentos em jogo no espaço educativo; e elege instrumentos auxiliares de ensino: os recursos metodológicos a cada objetivo e ação (livro, giz, computador, ábaco, etc.). E por fim, os processos de análise e síntese, ao longo da atividade, são momentos de avaliação permanente para quem ensina e aprende.

A AOE remete, em seus fundamentos, à Teoria da Atividade (A. Leontiev) que, por sua vez, remete aos fundamentos marxistas (K. Marx). Retoma-se, aqui, alguns de seus fundamentos tanto para caracterizar a $\mathrm{AOE}$, quanto para - posteriormente - 
fazer as conexões necessárias com o projeto da Educação do Campo.

A característica fundamental do marxismo é ser uma filosofia materialista e histórica dialética. Para o materialismo, o ser pode existir sem a consciência, mas a consciência não pode existir sem o ser.

Os homens são os produtores de suas representações, de suas ideias e assim por diante, mas os homens reais ativos, tal como são condicionados por um determinado desenvolvimento das forças produtivas e pelo intercâmbio que a ele corresponde, até chegar às suas formações mais desenvolvidas. A consciência não pode jamais ser outra coisa que não o ser consciente, e o ser dos homens é o seu processo de vida real. (MARX; ENGELS, 2007, p. 94)

A consciência, esse conjunto de reflexos da realidade, é um produto histórico e surge ao longo de um processo de evolução da vida (RIGON, 2009). Antes de existir, o homo sapiens ou o homem como se conhece hoje, existiam seres vivos com um psiquismo que de alguma maneira refletiam a realidade, mas esses seres não possuíam consciência, essa maneira específica de refletir a realidade, esses seres vivos não impunham sua vontade à natureza. Conforme Vygotsky (1997, p. 49), “a capacidade que tem nosso corpo de se constituir em excitante (por meio de seus atos) de si mesmo (e de cara a outros novos atos) constitui a base da consciência”. A origem da consciência está atrelada - portanto - à origem de uma especificidade da atividade humana que não se reduz à adaptação à realidade, que não é passiva como a dos animais em geral, pois o ser humano passa a transformar a realidade (natureza), a produzir instrumentos (ferramentas), a produzir os meios para a satisfação de suas necessidades.

Uma aranha executa operações semelhantes às do tecelão, e a abelha supera mais de um arquiteto ao construir sua colmeia. Mas o que distingue o pior arquiteto da melhor abelha é que ele figura na mente sua construção antes de transformá-la em realidade. No fim do processo de trabalho aparece um resultado que já existia antes idealmente na imaginação do trabalhador. Ele não transforma apenas o material sobre o qual opera; ele imprime ao material o projeto que tinha conscientemente em mira, o qual constitui a lei determinante do seu modo de operar e ao qual tem de subordinar sua vontade. E essa subordinação não é um ato fortuito. Além do 
esforço dos órgãos que trabalham, é mister a vontade adequada que se manifesta através da atenção durante todo o curso do trabalho. (MARX, 1999, p. 212).

Percebe-se - nesse excerto - uma atividade social movida por fins conscientes (atividade teleológica). O homem faz isso por uma antecipação mental do tipo de atividade que ele espera alcançar após sua ação: o ser humano antecipa mentalmente os resultados de sua atividade, os resultados do trabalho. Um dos elementos do processo de trabalho é a realização de uma atividade adequada a um fim. Essa antecipação da atividade humana guia a atividade; por meio dessa antecipação, o ser humano age, põe em movimento suas capacidades, suas forças para atingir, ao final da atividade, algo que antes não existia. Isto é, um "objeto" passa a existir como consequência da ação humana, da ação intencional. Para Leontiev (1978, p. 68), as atividades humanas "são processos psicologicamente caracterizados por uma meta a que o processo se dirige (seu objeto) coincidindo sempre com o objetivo que estimula o sujeito a executar esta atividade, isto é o motivo".

A matéria, o ser, existia antes da consciência, resultado do trabalho, da atividade teleológica. O ser existe, o fenômeno existe, mas ainda não existe a consciência dele. A consciência é o ser em atividade, realizando atividade consciente, direcionando os processos objetivos. O homem - nesse aspecto - é produto e produtor da história. Conforme Marx (2003) ${ }^{3}$, os homens fazem a história, mas não como a querem, fazem-na em circunstância determinadas. Em circunstâncias historicamente determinadas, da qual eles mesmos são os criadores. O ser humano é uma realidade concreta, e sua essência é constituída nas relações sociais.

Há uma série de outras concepções naturalizantes, biologizantes, dentre outras, que apontam uma compreensão contrária, no sentido de que o ser humano ou sua consciência é resultado daquilo que o código genético determina ou condicionada exclusivamente pelo meio, inclusive, estruturalmente, similares às concepções religiosas. Afinal, apontar o código genético ou deus como determinantes do ser humano, seu comportamento e sua consciência, uma vez

\footnotetext{
3 "Os homens fazem sua própria história, mas não a fazem como querem; não a fazem sob circunstâncias de sua escolha e sim, sob aquelas com que se defrontam diretamente, legadas e transmitidas pelo passado." (MARX, 2003, p. 7).

Obutchénie: R. de Didat. e Psic. Pedag.|Uberlândia, MG|v.4|n.2|p.310-333| maio/ago. 2020 ISSN: $2526-7647$ 
que não se consegue influir, são perspectivas semelhantes.

A consciência nasce na atividade humana e é ao mesmo tempo apropriação da natureza quando o ser humano começou a produzir cultura, que na compreensão mais geral, é a pedra lascada, o domínio do fogo etc. O homem se apropria dos bens da natureza e os transforma, inserindo-os nas práticas sociais. Ocorre uma incorporação à atividade humana de modo que, por exemplo, a pedra se transforma em faca. Ao lascar a pedra, contudo, transfere atividade para os objetos, transfere algo para o objeto. Essa é a configuração do processo de objetivação e subjetivação (apropriação).

Uma definição simples de objetivação é de que ela é a transferência da atividade do sujeito para o objeto; e o objeto passa a ser portador de características da atividade do sujeito. Uma pedra lascada, um instrumento, não é mais um objeto natural, produto apenas da natureza, mas sim produto da atividade humana (atividade social ou atividade cultural). Reitera-se, esse é o processo de objetivação, a transferência de atividade física, mental e biológica para o objeto. $\mathrm{E}$, com a objetivação, o ser humano produz uma realidade que não é mais a natural, isto é, essa realidade é um produto da cultura (RIGON, 2011, p. 35).

Cultura é atividade humana objetivada de maneira historicamente cumulativa. A atividade se acumula na cultura, essa, por sua vez, é uma condensação da atividade. A atividade humana condensada na cultura, portanto, não é só atividade física, mas também mental e biológica que se apresentam enquanto produtos da cultura humana.

O conhecimento é atividade humana objetivada, é a atividade de domínio pela consciência da realidade, das circunstâncias reais nas quais o sujeito está inserido. Nesse caso, os conteúdos escolares a) quando são organizados de modos a possibilitar, pelos alunos, o domínio do conhecimento nas suas formas mais elaboradas da produção humana; b) quando a didática e o currículo se organizam a partir do que há de mais desenvolvido em termos de conhecimento (científico, artístico, filosófico e outros); c) quando o educando se apropria disso, ele está se apropriando de atividade humana. Essa apropriação, mediada pelo ensino 
sistemático, organizado, pelo professor, faz com que a atividade que estava latente no conhecimento seja trazida à vida novamente. Os alunos reproduzem em sua ação aquilo que foi produzido e acumulado historicamente pelo conjunto dos homens. Um exemplo desse aspecto é o jogo, que é a maior parte das atividades das crianças, uma vez que reproduzem processos que não existem mais enquanto atividade humana, mas estão condensadas enquanto cultura, enquanto jogo, enquanto atividades lúdicas. O desenvolvimento e a aprendizagem ocorrem por meio da apropriação de conceitos, de modos de gerais de atividade, em meio "a atividades culturais": dança, jogos, vivências etc. A criança, num primeiro momento, não elabora seu próprio conhecimento, mas o interioriza, interioriza a experiência histórica da humanidade.

Trabalho educativo é a produção nos indivíduos da humanidade que foi produzida historicamente: é uma reprodução, mas sobre novas bases, no indivíduo. $\mathrm{O}$ indivíduo não tem que refazer a história novamente. Não recomeça do zero. A criança, em poucos anos de vida, desenvolve coisas que a humanidade levou milhares de anos para desenvolver; não o faz espontaneamente, não faz por si mesma, senão por meio de sínteses da atividade histórica, senão reproduzindo no jogo aquilo que está ou esteve presente como trabalho (atividade humana social vital). A educação escolar, nesse sentido, deve não somente satisfazer as necessidades do indivíduo, mas produzir necessidades superiores, criar condições para que ocorra o domínio da natureza externa e o desenvolvimento das funções psíquicas superiores (domínio da natureza interna).

Com base nesses elementos, a teoria da atividade e seus fundamentos nos remetem aos seguintes princípios: 1) o caráter ativo do sujeito da atividade; 2) o surgimento da psique como necessidade da vida; 3) mudança das leis biológicas para as leis culturais; 4) a unidade entre a atividade interna e a atividade externa.

A partir dos estudos de Moura (1996, 2001, 2010) e seus colaboradores, é possível afirmar - na mesma direção - que a ação educativa em sala de aula se realiza enquanto atividade a partir do momento em que consegue desenvolver nos sujeitos um modo geral de apropriação da cultura humana, um modo geral de 
resolver problemas autênticos. A AOE, neste quesito, pressupõe a existência de uma situação ou problema desencadeador da aprendizagem de modo que, na sua sequência, ocorra a interação entre os sujeitos (professores e alunos) enquanto solucionam o problema - coletivamente e mediados pelo conteúdo (aquilo que já foi desenvolvido pela humanidade) - ao mesmo tempo em que se apropriam da experiência histórica e social da humanidade, afinal, reitera-se, "não é necessário reinventar a roda”, mas se apropriar daquilo que está objetivado na cultura.

Não se pode deixar de trazer à baila a manifestação da alienação nesse processo. A alienação não é um fenômeno que nasce na consciência do indivíduo, a alienação é um fenômeno social. Sinteticamente a alienação é um fenômeno histórico social que a humanidade, o gênero humano, desenvolve; a atividade humana produz conquistas enormes para a humanidade, no sentido de bens materiais, recursos materiais, para uma existência digna para os seres humanos, e recursos não materiais. Tudo isso é produzido por meio de relações sociais de produção que colocam os seres humanos, a grande maioria dos sujeitos, em escasso acesso a essa riqueza material e não material produzida. Por exemplo, se o ser humano passa fome, quando há condições para que isso não aconteça, isso nos diz algo sobre as condições de liberdade do sujeito: é um problema ético-político: o problema da fome, é um problema de alienação. Alienação não no sentido de que o sujeito não tem conhecimento de que tipo de alimentos pode comer, usufruir, mas no sentido de que a humanidade pode produzir e produz alimentos em quantidade suficiente, mas esses indivíduos não têm acesso. O não acesso ocorre, na sociedade capitalista, porque tudo o que é produzido é mercadoria, e, para ser apropriado, precisa ser trocado por dinheiro. Então os indivíduos passam fome por não possuírem as condições (dinheiro) para adquirir o alimento. Não é um problema de tecnologia, de capacidade humana de produzir alimento, mas é um problema decorrente da organização social, da organização das relações sociais de produção. Isso é alienação: aquilo que o próprio ser humano criou que impede a humanidade de acessar o resultado da própria atividade humana. Quem não tem terra não tem - 
inclusive - as condições, os meios para produzir quaisquer tipos de alimento. Nesse caso, não é um problema de falta de conhecimento, mas de acesso aos meios de produção em vista da propriedade privada.

Essa forma básica de alienação se desdobra em muitas outras. Uma delas é o trabalho assalariado na sociedade capitalista, não só porque esses trabalhadores não se apropriam dos bens, dos produtos, do seu trabalho, mas também porque esses não escolhem a atividade. A consequência disso é que ele não se torna mais humano na atividade; os sujeitos trabalham em troca de salário, portanto, o que dá sentido não é seu conteúdo, mas o salário, aquilo que recebe em troca.

O analfabeto não se afasta deliberadamente da língua escrita, mas está inserido num processo de alienação na sociedade que não o permite acessar esse bem produzido historicamente. Alienação como fenômeno social se desdobra e se apresenta em várias formas, atinge todas as dimensões da vida humana provocando esvaziamento das relações humanas, fazendo com que as pessoas não se relacionem pelo conteúdo, mas mediados pelo dinheiro, pela troca.

O ser humano ao realizar uma atividade consciente nem sempre está tendo uma relação de consciência com a atividade, ou seja, a consciência da atividade consciente. A atividade é consciente por que é dirigida por fins. O trabalho pode ser uma atividade consciente e alienada ao mesmo tempo; quanto mais alienada, mais dispêndio de atenção para realizar a atividade será necessário, que é o caso do operário na sociedade capitalista. Quanto mais alienada a atividade, maior deverá ser o grau de atenção para realizar a atividade, mais a consciência deve estar concentrada para alcançar os objetivos da atividade.

Relação consciente com a atividade é estabelecer relação com os fins se segue e as razões pelas quais se quer alcançar esse fim, isto é, a relação entre o significado da atividade e o seu sentido, o que se faz e por que se faz algo. A grande questão é que o alienado se confunde com o espontâneo; esse não é consciente. Muitas coisas se fazem de modo automático, espontâneo, o que pode ser necessário para viabilizar a vida humana. O problema é quando se faz necessário suspender essa espontaneidade, e não se consegue pelos diversos 
motivos. A língua materna, na forma de língua falada, é resultado de uma aprendizagem espontânea; contudo, em alguns momentos ou em determinadas condições, ele necessita falar, usar conceitos de modo consciente, para explicar determinado fenômeno - por exemplo -, é quando há a necessidade de fazer uso consciente da língua. No ambiente escolar, no caso, o indivíduo precisa ser ensinado naquilo que ele não consegue aprender sozinho ou não teria acesso sozinho, no seu grupo, na sua comunidade.

A vida cotidiana, embora não seja necessariamente a esfera mais alienada, é a esfera mais propensa à alienação devido à espontaneidade, ao caráter pragmático do cotidiano e ao ativismo resultante das circunstâncias da vida cotidiana. A vida cotidiana está posta como a "base de todas as reações espontâneas dos homens ao seu ambiente social, na qual, frequentemente parece atuar de forma caótica" (HELLER, 1977, p. 12).

Revolução não é somente a transformação da realidade externa dos indivíduos, mas também a transformação interna, a transformação dos indivíduos é parte imprescindível da transformação da sociedade. Pode-se afirmar que não há transformação dos indivíduos sem a participação deliberada, sistemática, organizada da educação escolar. Por isso que se defende que a educação escolar é um processo essencial da transformação da sociedade. Isso que dá sentido à perspectiva leninista quando ele declara que "não podemos nos manter no velho ponto de vista da instrução apolítica, não podemos organizar o trabalho de instrução desligado da política” (LÊENIN, 1982, p. 400).

A partir da AOE (MOURA, ARAUJO, SERRÃO, 2019, p. 421/422),

Ao considerar o conhecimento como produção humana, decorrente de um movimento lógico e histórico de formação de conceitos, o professor, como sujeito da atividade de ensino, pode criar situações desencadeadoras de aprendizagem com a clara intencionalidade de promover as condições pedagógicas para que a criança entre em atividade de estudo, objetivando a apropriação de conhecimentos teóricos, constituintes de um projeto político-pedagógico de formação das potencialidades humanas. 
Para Leontiev, não pode existir atividade se não existir motivo, isto é, não tem atividade, aprender matemática, ciências da natureza, filosofia, artes (e outras ciências) se não houver para a criança, sujeito da aprendizagem, um motivo. Por isso se faz necessário organizar situações que podem desencadear a aprendizagem, afinal, nem todo o ensino conduz ao desenvolvimento e nem sempre aquilo que ser faz, com pretensão formativa ou pedagógica, conduz a formação de conceitos e ao pensamento teórico (Davidov), desenvolvimento da zona de desenvolvimento proximal (Vigotski). Poder ser uma vivência agradável, um momento lúdico, mas não conduz ao desenvolvimento, não conduz à formação de conceitos teóricos que são elementos fundamentais para o desenvolvimento do sujeito.

A AOE se apresenta - assim - como uma base teórico-metodológica necessária, em seus fundamentos e práticas, para o trabalho de instrução, para o desenvolvimento da atividade pedagógica na direção da transformação social. Possui uma implicação fundamental: mudança radical de nossa compreensão, dos resultados e da organização de ações de ensino e aprendizagem.

\section{Atividade Orientadora de Ensino e sua Conjunção com a Educação do} Campo: Notas conclusivas

Uma das questões que se buscou responder foi a anunciada de como organizar o processo educativo para que atenda às perspectivas e o contexto do campo e dos camponeses? No intuito contextualizar a resposta, foram retomados e discutidos alguns elementos da Educação do Campo e da Atividade Orientadora de Ensino que demonstram as relações necessárias e possíveis de serem estabelecidas entre um projeto de Educação de transformação e os pressupostos do modo de organização do ensino que contemplem os problemas autênticos deste projeto. Certamente outros textos desse Dossiê contribuirão - especialmente para a definição da Atividade Orientadora de Ensino, porém, destacam-se algumas notas que podem ser extraídas desse estudo.

Do projeto de Educação do Campo, requer-se uma educação cuja função precípua seja a formação de sujeitos críticos, que ofereça instrumentos práticos e 
teóricos para que se pensem novas alternativas de desenvolvimento social dos sujeitos do campo. Se um dos princípios é a educação pelo trabalho e para o trabalho, a AOE traz em seus fundamentos a mesma estrutura, quando sistematiza para o processo de ensino (conteúdo e currículo) elementos do conhecimento concebidos no movimento lógico e histórico de formação de conceitos.

O desenvolvimento da criança depende da organização da atividade, da organização do ensino, caso contrário não ocorre. Retomando: a ação (de aprendizagem, ações intelectuais) é um processo dirigido a um objetivo consciente. A estrutura da atividade comporta: motivo, objetivo, base orientadora da ação, sequência de operações e o resultado ou produto. Visitar uma pirâmide não é suficiente para aprender conceitos históricos, de arquitetura, conceitos geométricos; visitar um assentamento ou acampamento (MST) não é suficiente para entender as lutas históricas, para aprender conceitos de classes, de agroecologia, de desenvolvimento rural, produção sustentável e outros. Objetivo da etapa escolar é formar conceitos científicos, desenvolver aptidões básicas dentro de ações intelectuais correspondentes.

Enquanto princípio da Educação do Campo, as relações de competição precisam ser transformadas em relações de cooperação, de apoio mútuo. Isto também é elemento fundamental da AOE, em seus aspectos teóricometodológicos, pois - para a solução do problema desencadeador da aprendizagem - concebe-se como necessário que ocorram interações entre professores e alunos mediados pelo conteúdo, o que resulta, por seu turno, na superação da propriedade privada do conhecimento.

A superação da propriedade privada é a emancipação plena de todos os sentidos e qualidades humanas; porém, é esta emancipação precisamente porque todos estes sentidos e qualidades tomaram-se humanos, tanto no sentido objetivo quanto subjetivo. O olho tornou-se um olho humano, assim como seu objeto tornou-se um objeto social, humano, criado pelo homem para o homem. Os sentidos se tornaram, assim, imediatamente teóricos na sua prática. (MARX; ENGELS, 2011, p. 50). 
Assim corrobora-se que o ponto de partida, inclusive para a produção do conhecimento, são as circunstâncias históricas e de vida, que, embora coincidam com o seu ponto de chegada, este precisa ser um concreto pensado, sistematizado, que supere a cotidianidade no sentido espontaneísta. Esse processo demonstra tanto a condição do processo de humanização, haja vista que nossos sentidos são resultados da atividade humana consciente (direcionada por fins), quanto a possibilidade de que, somente com a superação da propriedade privada ${ }^{4}$, haverá a superação dos processos de alienação. Essa tarefa, é uma atividade pedagógica que precisa ser conduzida por professores.

Deve dizer-se que as centenas de milhares de professores constituem o aparelho que deve impulsionar o trabalho, despertar o pensamento, lutar contra os preconceitos que ainda existem nas massas. A herança da cultura capitalista, o fato de que a massa dos professores está impregnada com os seus defeitos, com os quais essa massa não pode ser comunista, não pode, no entanto, impedir que se integrem esses professores nas fileiras dos trabalhadores da instrução política, porque estes professores possuem conhecimentos sem os quais não podemos alcançar os nossos objetivos. (LÊNIN, 1982, p. 404/405).

A tarefa dos educadores - nesse caso - não é e não pode ser somente o de compor o quadro docente das escolas e instituições de ensino e aprendizagem em sua atividade específica, mas de compor as fileiras da instrução pública vencendo as barreiras capitalistas e burguesas, promovendo a transformação das massas, promovendo a educação crítica e política; afinal, somente assim é possível incorporar uma nova concepção de mundo e um novo sistema social. É necessário explicitar o compromisso político assumido, pois a ação pedagógica carrega em si a dimensão ético-política no seu exercício.

\footnotetext{
${ }^{4}$ Salienta-se que é superação da propriedade privada dos meios de produção. A formação da cultura colaborativa por meio da educação, acesso amplo ao ensino gratuito em todos os níveis, da "consciência ambiental" de que os recursos naturais são finitos e muitos não se renovam e de que nesse ritmo de produção/exploração seriam necessários muitos planetas para dar conta das futuras gerações, são alguns passos iniciais para essa superação. Nesse tempo pandêmico tem-se pensado na direção de que se não há essa perspectiva coletiva, de colaboração e cuidado com o outro, coloca-se em risco uns aos outros, comprometendo, inclusive, as futuras gerações. É premente estimular a solidariedade! 
Não é possível democratizar o ensino de um país sem democratizar sua economia e sem democratizar, finalmente, sua superestrutura política. Num povo que cumpra conscientemente seu processo histórico, a reorganização do ensino deve estar dirigida por seus próprios homens. (MARIATEGUI,2008, p.127).

Enfim, precisa-se dizer que não basta mais somente o conhecimento, mas esse tem de vir junto com o engajamento político, com a organização social da classe trabalhadora. Não interessa mais a formação apressada (acúmulo de informações), mas somente o conhecimento, a apropriação da cultura e da atividade social (trabalho) que nela está condensada, de modo a promover a emancipação humana. A atividade educativa não é e não se resume apenas ao processo de comunicação; para tanto, contribui a AOE - como base teóricometodológica para se realizar essa tarefa revolucionária por meio da atividade pedagógica no processo de ensino e aprendizagem escolar. Não é espontaneamente que se promoverá a transformação social, mas por meio de um movimento (uma atividade) que se coloque essa tarefa conscientemente.

\section{Referências}

BRASIL. Decreto n. ${ }^{\circ}$ 7.352, de 4 de novembro de 2010. Dispõe sobre a política de educação do campo e o Programa Nacional de Educação na Reforma Agrária PRONERA. http://portal.mec.gov.br/docman/marco-2012-pdf/10199-8-decreto7352-de4-de-novembro-de-2010/file.

BRASIL. Parecer CNE/CEB 1-Diretrizes Operacionais para a Educação Básica nas Escolas do Campo, de 3 de abril de 2002.

http://pronacampo.mec.gov.br/images/pdf/mn resolucao \%201 de 3 de abril d e 2002.pdf.

CALDART, R. S. Por uma educação do campo: traços de uma identidade em construção. In: CALDART, R. S.; KOLLING, E. J.; CERIOLI, P. R. Educação do Campo: identidade e políticas públicas. Brasília, DF: Articulação Nacional Por uma Educação do Campo, 2002.

CALDART, R. S. Sobre educação do campo. In: SANTOS, C. A. dos (org.). Por uma educação do campo: Campo - Políticas Públicas - Educação. Brasília: INCRA/MDA, 2008, p. 44-74.

HELLER, A. Sociología de la vida cotidiana. Barcelona: Península, 1977. 
LÊNIN, V. U. Que fazer? Lisboa/Portugal: Editorial Avante, 1978.

LÊNIN, V. U. Discurso na conferência de toda a Rússia dos comitês de instrução política das seções de Gubérnia e Uezd da instrução pública. In: Obras

Escolhidas. Tomo 3. Lisboa/Portugal: Edições Avante, 1982.

LÊNIN, V. U. As três fontes. $4^{\mathrm{a}}$ reimpressão. São Paulo: Expressão Popular, 2009.

LEONTIEV, A. O desenvolvimento do psiquismo. Lisboa: Horizonte Universitário, 1978.

LURIA, A.R. Desenvolvimento Cognitivo. São Paulo: İcone, 1990.

MARIÁTEGUI, J. C. Sete ensaios de interpretação da realidade peruana. São Paulo: Expressão Popular, 2008.

MARX, K. O Capital: crítica da economia política. Rio de Janeiro: Civilização Brasileira, 1999.

MARX, K. O 18 Brumário de Luiz Bonaparte. São Paulo: Centauro, 2003.

MARX, K.; ENGELS, F. A ideologia alemã - Crítica da mais recente filosofia alemã em seus representantes Feuerbach, B. Bauer e Stirner, e do socialismo alemão em seus diferentes profetas (1845-1846). São Paulo: Boitempo, 2007.

MARX, K.; ENGELS, F. Textos sobre Educação e Ensino. Campinas, SP:

Navegando, 2011.

MOURA, M. O. A atividade de ensino como unidade formadora. Bolema, São Paulo, ano II, n. 12, p. 29-43, 1996.

MOURA, M. O. A atividade de ensino como ação formadora. In: CASTRO, A.; CARVALHO, A. (Org.). Ensinar a ensinar: didática para a escola. São Paulo: Pioneira, 2001.

MOURA, Manoel Oriosvaldo de Moura et al. A atividade pedagógica na teoria histórico-cultural. Brasília: Liber, 2010.

MOURA, M. O.; ARAUJO, E. S.; SERRÃO, M. I. B. Atividade Orientadora de Ensino. Linhas Críticas: v. 24, 2019. https://doi.org/10.26512/lc.v24i0.19817.

PRADO JÚNIOR, C. A Revolução brasileira. São Paulo: Brasiliense, 1977. 
RIGON, A. J. O desenvolvimento psíquico na teoria histórico-cultural. Passo Fundo: UPF Editora, 2009.

RIGON, A. J. Ser sujeito na atividade de ensino e aprendizagem. 2011. Tese (doutorado). Faculdade de Educação, Universidade de São Paulo, São Paulo, 2011.

SAVIANI, D. Pedagogia histórico-crítica: primeiras aproximações. $8^{\mathrm{a}}$ ed. Campinas, SP: Autores Associados, 2003.

VYGOTSKY, L. S. Obras Escogidas. Madrid: Visor, 1997, V.1

VIGOTSKI, L. S. Manuscrito de 1929. Educação \& Sociedade, Campinas/SP, v. 71, n. especial, p. 21-44, 2000. 